\title{
Carla Viola: \\ Information ethics and information literacy: A material-historical study between capital and class struggle in the Marxian perspective
}

\begin{abstract}
:
The present article analyzes ethics in Karl Marx perspectives, going through information ethics and information literacy that permeate individuation and class struggle in capitalist society. The objective is to approach critical reflection about dominated and dominant class's ethics values proclaimed by author. In order to provide the desired research, I did literature review and digital documents consultation about the themes. Through this work, it is possible to identify that the author's description of reality through historical materialism sought the dissemination of ethics through the ascertainment that individuals generate their stories, but these are not linked to their wills but directly linked to class formation and struggle as factors determining the circumstances under which the reality of society is constituted. It implies the search for mastery of language codes and information literacy to know, seize and disseminate information ethics aiming at the effective strategies elaboration to combat the ruling class hegemony.
\end{abstract}

\section{Agenda:}

Introdução 52

Sintomas que evidenciam a Ética 53

Informação e a Ética do Capital 54

Competência em Informação e a Luta de Classes . 56

Conclusão 59

Author:

Carla Viola:

- Lawyer, degree in advertising, Master's degree in the Post-Graduate Programe in Information Science (PPGCI), Instituto Brasileiro de Informação em Ciência e Tecnologia (IBICT) e Universidade Federal do Rio de Janeiro (UFRJ). Rio de Janeiro. Brasil

- 正 + 55 - 021 - 97239-8649, $\bowtie$ viola.carla@gmail.com

- Relevant publication:

- Transparência da Informação e Ética da Comunicação: Um estudo político-social sobre o Portal da Câmara dos Deputados: ULEPICC, Brasília, Brasil, 2016, 15 p.

- A individuação da mulher na política entre dominação, objetos técnicos e dispositivo de enunciação: 13a edição Women's Worlds Congress \& Fazendo Gênero 11, Florianópolis, Brasil, 2017, 13p.

- Um estudo do cenário jurídico-social do acesso à informação no Brasil: XIII CINFORM, Salvador, Brasil, 2017, 15 p. 


\section{Introdução}

Os dilemas éticos implícitos e explícitos da atualidade permitem que se pondere sobre acepções, confluências e divergências dos valores morais visando a investigação das questões que envolvem a conformação da informação e da competência em informação a partir das teorias e práticas político-econômicas.

Marx deu à dialética a configuração materialista necessária para adequá-la ao trabalho científico, possibilitando inferências sobre o conceito de ética no sistema capitalista e seus regentes sociais e políticos.

Nesse sentido, para a melhor apropriação dos conceitos, Schneider dispõe que eles

"Só podem ser adequadamente compreendidos à luz de sua relação muitas vezes antagônica e contraditória com o universo conceitual no qual fazem sentido e com o real extra conceitual, bem como com outros conceitos específicos, e, é claro, consigo mesmos. Em todas essas relações, a mediação de um terceiro elemento é sempre necessária para uma adequada compreensão de sua natureza/identidade dinâmica e para a superação de eventuais antinomias internas ou externas (de um conceito consigo mesmo, entre um conceito e outro conceito, entre um conceito e um universo conceitual ou entre conceitos e fatores extra conceituais)". ${ }^{1}$

Seguindo esses preceitos, adota-se, para fundamentar a teoria abordada, o conceito de informação à luz da compreensão de Wilden (2002), Capurro e Hjorland (2007). Os estudos sobre ética, códigos linguísticos, formação e luta de classes são realizados de acordo com Aristóteles (2014), Marcondes (2015), Bernstein (2003), Marx (2007, 2011, 2013) e Eagleton (2012). Já as deduções sobre competência em informação são embasadas pelos preceitos do Association of College and Research Libraries Board (ACRL Board) (2015) e Elmborg (2012) e a concepção de individuação, inspirada em Simondon (2005).

Para amparo da investigação pretendida, realizaram-se consultas bibliográficas e documentais, buscando reflexões sobre os principais termos e expressões versados.

Assim, para estabelecer referenciais teóricos entre informação, competência em informação, formação e luta de classes, fazem-se inferências sobre ética, de acordo com Marcondes, em três dimensões. Em primeiro lugar encontra-se o sentido básico, ou seja, a ética como o conjunto de costumes, hábitos e práticas de um povo. Em segundo lugar, a ética se apresenta como sistema em sentido normativo, isto é, como conjunto de preceitos que estabelece valores e deveres. Por fim, em terceiro lugar, a ética tem um sentido reflexivo ou filosófico que diz respeito as teorias e concepções. ${ }^{2}$

Dito isso, primeiramente, tecem-se os sintomas éticos para se fazer alusões aos fenômenos e virtudes morais, englobando o conhecimento adquirido pelas práxis. Em um segundo momento, evidenciam-se as confluências entre as dialéticas da informação e da ética do capital. No último tópico, busca-se tematizar referências sobre competência em informação, códigos linguísticos, formação e luta de classes, salientando questões teóricas e práticas da ética exercida em seus contextos. Finaliza-se com o corolário das vertentes que abrangem a ética em informação nas realidades costumeiras da economia política.

\footnotetext{
${ }^{1}$ Schneider, Marco: A Dialética do Gosto: Informação, Música e Política. 212

2 Marcondes, Danilo: Textos básicos de ética: de Platão a Foucault. 10
} 


\section{Sintomas que evidenciam a Ética}

As doutrinas éticas fundamentais nascem e se desenvolvem em diferentes épocas e sociedades como respostas aos problemas básicos apresentados pelas relações entre os homens, e, em particular, pelo seu comportamento moral efetivo. ${ }^{3}$

Informações, princípios, conceitos, valores e normas estão representados na realidade social de uma época. Assim, as bases morais são apreendidas e reconhecidas com apoio do momento histórico-social que se deseja pesquisar. Contudo, os fundamentos da ética são nativos dos preceitos de sustentação das boas práticas.

Segundo os ensinamentos de Aristóteles, "toda arte, toda investigação e igualmente toda ação e projeto previamente deliberado parecem objetivar algum bem. Por isso se tem dito, com razão, ser o bem a finalidade de todas as coisas". ${ }^{4}$ Manifestações, sensações, percepções e inspirações que contemplem o bem em sua essência terminam por englobar sintomas éticos inerentes ao ser humano.

Como bem explica Aristóteles, "parece, portanto, como tem sido afirmado que o ser humano é o princípiofundamento das ações e que cabe à deliberação ocupar-se das ações a serem realizadas pelo próprio agente, estando ciente de que todas as nossas ações visam a fins que são distintos delas mesmas". ${ }^{5}$

Para se identificar as práticas morais desejáveis, observa-se, na linha do pensador, a doutrina do meio-termo por ser um critério de análise das diversas manifestações sintomáticas do indivíduo na práxis das inferências éticas.

Aristóteles estabelece que a mediania de uma coisa é "um ponto equidistante de cada um dos extremos, que é um e o mesmo para todos", contudo para a mediania relativa ao indivíduo é "aquilo que não é nem excessivamente grande, nem excessivamente pequeno, o que não é um e o mesmo para todos". ${ }^{6}$

Ademais, essa mediania eleita pelo singular "evita o excesso e a deficiência, procurando e elegendo o ponto mediano", permitindo que tal atitude qualifique o indivíduo de virtuoso por fazer "as coisas certas, para o propósito certo e da maneira certa" correspondendo "à justa medida (mediania), a qual é a marca da virtude".7

Contudo, observa-se que nem sempre o que parece moralmente correto em uma situação, será moralmente adequado em outra situação. Importa avaliar, no momento em que se vai implementar essa ou aquela atitude, quais são os elementos que compõem o evento em si e qual singularidade ou particularidade, ou até mesmo universalidade está em questão.

Segundo Aristóteles, "a virtude moral ou ética é o produto do hábito, sendo o seu nome derivado, com uma ligeira variação dessa palavra". 8 É incontestável que a prática leva à perfeição, estando o indivíduo suscetível à constância do exercício moral, para se alcançar a excelência ética.

\footnotetext{
${ }^{3}$ Sánchez Vázquez, Adolfo: Ética. 269

${ }^{4}$ Aristóteles. Ética a Nicômaco. 45

${ }^{5}$ Aristóteles. Ética a Nicômaco. 117

${ }^{6}$ Aristóteles. Ética a Nicômaco. 91

${ }^{7}$ Aristóteles. Ética a Nicômaco. 92

${ }^{8}$ Aristóteles. Ética a Nicômaco. 81
}

\section{Carla Viola:}


Assim, encaminhar o comportamento na direção da ética e exercê-lo com habitualidade resulta em frequentes ações morais envolvidas por adequadas informações utilizadas em contextos corretos, proporcionando a busca do bem como finalidade primordial. Esse bem se alicerça na felicidade alcançada de forma justa e moderada, referendada pelo cuidado de si e dos outros.

Nessa conjuntura, ações virtuosas provêm da excelência de caráter, possibilitando o implemento de ações positivas e, consequentemente, informações profícuas. De acordo com Sánchez Vázquez "a virtude supõe uma disposição estável ou uniforme de comportar-se moralmente de maneira positiva; isto é, de querer o bem" .

Esse comportamento exige moderação, ou seja, temperança para que se possa avaliar as atinências morais da informação e da ação. Quer em situações estáveis ou instáveis, é necessário avaliar com ponderação o implemento das atitudes requeridas em razão dos elementos informacionais apresentados.

Outrossim, Aristóteles aduz que "o indivíduo moderado é aquele que anseia pelas coisas devidas, da maneira devida e oportunamente, que é o que determina a razão". ${ }^{10}$ As questões devidas e oportunas são em diversas situações coroadas pela generosidade que requer se doar ao próximo, sem esperar a contraparte. Ao desenvolver o tema, Aristóteles argumenta que:

"O generoso destaca-se mais por dar aos indivíduos certos do que por obter riqueza das fontes certas e não obter das erradas. Com efeito, a virtude consiste mais em beneficiar do que ser beneficiado e mais em realizar atos nobres do que não realizar atos vis, mas é evidente que beneficiar e agir nobremente se relacionam com dar, ao passo que ser beneficiado e não realizar atos vis se relacionam com o obter".11

Outros sintomas, que merecem destaque no percurso da primazia da conduta ética, são a prudência e o discernimento, que exigem referenciais equânimes e análogos para a justa decisão. Ambos são faculdades do indivíduo, as quais tornam possíveis o exercício de ações morais pertinentes.

Ainda para Aristóteles, o discernimento se ocupa daquelas coisas que se pode questionar e deliberar, sendo seus objetos "os mesmos da prudência, o que não quer dizer que discernimento e prudência sejam idênticos, pois enquanto esta última emite comandos (já que seu fim é instruir sobre o que se deve fazer ou não fazer), o discernimento se limita a julgar". ${ }^{12}$

A partir dessas reflexões éticas, sai-se da ciência da política dos meandros da busca do bem comum de Aristóteles, para concentrá-la no lugar concreto da luta pelo poder, operando o deslocamento da economia política para a luta de classes e os dédalos do capital elucidados por Marx.

\section{Informação e a Ética do Capital}

O conceito de informação, como preceituado por Wilden, se alarga para além de sua significação fundamental e cotidiana de dar estrutura ou forma, englobando dois sentidos. O primeiro se limita ao âmbito técnico que

\footnotetext{
${ }^{9}$ Sánchez Vázquez, Adolfo. Ética. 214

${ }^{10}$ Aristóteles, Ética a Nicômaco. 141

${ }^{11}$ Aristóteles, Ética a Nicômaco. 146

${ }^{12}$ Aristóteles, Ética a Nicômaco. 237
}

\section{Carla Viola:}


considera a informação como uma quantidade (mensurável em bits) e o segundo é "a informação qualitativa, antes de ser quantitativa"13.

Revelando questões que fariam parte das características qualitativas da informação, Wilden entende informação como a organização de uma variedade real que se apresenta nas

"Estruturas, formas modelos, figuras e configurações; em ideias, ideais e ídolos; em índices, imagens e ícones; no comércio e na mercadoria; em continuidade e descontinuidade; em sinais, signos, significantes e símbolos; em gestos, posições e conteúdos; em frequências, entonações, ritmos e inflexões; em presenças e ausências; em palavras, em acções e em silêncios; em visões e em silogismos". ${ }^{14}$

Partindo dessa premissa, concebe-se capital como um conceito de conteúdo e significação abrangentes, inferindo a análise da ética em informação a partir de suas divisões, determinações e utilidades. Capital é um termo cunhado na visão marxiana não só por seu sentido valorativo, como também na variedade de informações que dele deriva.

No texto "Capital fixo e desenvolvimento das forças produtivas da sociedade" ${ }^{15}$, Marx descreve o "capital fixo" como "meio de produção" (ou seja, "meios de trabalho") que se consome no próprio processo de produção, isto é, ele é o "agente" que transforma a matéria-prima em produto. No que concerne à sua existência material, como material de trabalho, o capital se divide em proporções quantitativas diferentes entre si, perfazendo-se em três elementos: "material de trabalho", "meios de trabalho" e "trabalho vivo". Esses elementos, de valor diferenciado, são fundamentais para o próprio "processo do trabalho" do qual o próprio capital se apropria.

Diferentemente, o "capital circulante", composto de "matéria-prima" e "produto", apresenta-se como a diferença qualitativa do capital enquanto determinante de seu movimento como um todo.

Já a "atividade do trabalhador" é determinada e regulada pelo movimento da maquinaria. Tal atividade apenas medeia o trabalho das máquinas, supervisionando-as e mantendo-as livre de falhas. A tendência do capital é o "aumento da força produtiva do trabalho" e a "máxima negação do trabalho necessário", transformando o meio de trabalho em maquinaria. Assim, o valor objetivado das máquinas, que forma o produto, se contrapõe ao trabalho vivo, ou seja, a força produtiva formada pela acumulação de saber e da habilidade, que é absorvida pelo capital.

O capital confere a si mesmo a forma adequada no interior do "processo de produção", fazendo da maquinaria a forma mais adequada do "valor de uso", do "capital fixo". Ele promove, assim, a manutenção do trabalho em um ramo de produção pelo "trabalho coexistente", que, em outro ramo do capital, quando se põe como mediador entre os diferentes trabalhadores, aparece agora como qualidade do "capital circulante".

É nesse entrecho que o capital compartilha fenômenos éticos diferentes, dependendo das informações emanadas da sua essência funcional ou delegada. Ademais, o capital só emprega a máquina porque ela capacita o trabalhador a trabalhar uma parte maior do seu tempo para o capital, se apresentando apenas quando a força de trabalho é abundante.

\footnotetext{
${ }^{13}$ Wilden, Anthony. Informação. 11

${ }^{14}$ Wilden, Anthony: Informação. 11

${ }^{15}$ Marx, Karl: Grundrisse. 578-596
}

\section{Carla Viola:}


Para Marx fica evidente que o "meio de trabalho" torna o trabalhador independente e proprietário, e a "maquinaria", como "capital fixo", coloca-o apropriado e dependente. Assim, a troca de trabalho vivo por trabalho objetivado se apresenta como razão pela qual o trabalho social é colocado na forma de oposição entre o capital e o trabalho assalariado, sendo o último desenvolvimento da "relação de valor" e "da produção baseada no valor".

Importa destacar que cada interrupção do processo de produção influi diretamente como redução do próprio capital, fazendo com que o valor do "capital fixo" seja reproduzido na medida em que é consumido no processo de produção. Se não for utilizado, ele perde seu "valor de uso", deixando de passar o valor para o produto.

Como bem alerta Marx, o "próprio capital" é a "contradição em processo", pois procura reduzir o tempo de trabalho a um mínimo, ao mesmo tempo que, por outro lado, põe o tempo de trabalho como única medida e fonte da riqueza. A perspectiva do capital é criar "tempo disponível", se utilizando dos meios da arte e da ciência, para depois convertê-lo em trabalho excedente que é apropriado por ele, objetivando seu próprio desenvolvimento.

Assim sendo, Marx apresenta uma solução para tal contradição, sugerindo que a própria massa de trabalhadores se aproprie do seu trabalho excedente, convertendo-o em tempo disponível, permitindo, assim, que o tempo necessário de trabalho seja medido pelas necessidades do indivíduo social. Tal situação permitirá o rápido crescimento do desenvolvimento da força produtiva social, pois embora a produção tenha sido calculada com base na riqueza de todos, o tempo disponível de todos também aumentará. ${ }^{16}$

É nessa perspectiva, em que o tempo passa a trabalhar a favor do fluxo de informação e do conhecimento adquirido pelo trabalhador, se distanciando da ética dominada pelo capital, que se instiga a análise da competência em informação das classes em conflito.

\section{Competência em Informação e a Luta de Classes}

O ACRL Board, em suas orientações didáticas destinadas aos colaboradores, descreve competência em informação como "o conjunto de habilidades integradas que englobam a descoberta reflexiva da informação, a compreensão de como a informação é produzida, valorizando o uso da informação na criação de novos conhecimentos e a participação ética nas comunidades de aprendizagem". ${ }^{17}$

Quando os indivíduos idealizam a informação que deve ser valorada, transmitida e reproduzida, ela reflete princípios, conhecimento e o intelecto desse indivíduo. Tais elementos são componentes de sua competência em informação, usada para avaliar o código adequado para que sua mensagem seja reconhecida na sua classe e valorada em uma classe diferente, servindo inclusive como instrumento de luta por direitos reconhecidos.

Nesse contexto, Bernstein mostra que os códigos são induzidos pela relação social, expressando e regulando suas características e que a habilidade de alternar entre códigos restritos e elaborados termina por controlar a capacidade de mudar os papeis na relação social. Notadamente, nem todos os aspectos da estrutura social são traduzidos em elementos do código linguístico, mas se considera que os principais são assim traduzidos. ${ }^{18}$

\footnotetext{
${ }^{16}$ Marx, Karl: Grundrisse. 590-591

${ }^{17}$ ACRL Board. 3, tradução nossa

${ }^{18}$ Bernstein, Basil: Class, codes and control. 100-101
}

\section{Carla Viola:}


Deste modo, visando complementar tal concepção e, ainda, compreender as manipulações que ocorrem nas luta de classes, concebe-se, assim como Elmborg, que o indivíduo competente em informação:

"Consegue determinar a extensão das informações necessárias, acessar a informação necessária de forma eficaz e eficiente, avaliar criticamente as informações e suas fontes, incorporar informações selecionadas em sua base de conhecimento, usar a informação de forma eficaz para realizar um propósito específico, compreender as questões econômicas, legais e sociais que envolvem o uso da informação, e acessar e utilizar as informações eticamente e legalmente".19

Ao dominar as vertentes dos códigos e desenvolver tais competências, o indivíduo passa a ter capacidade de compreender as divergências existentes entre as classes sociais e maior capacidade de analisar e intervir nos contextos social, político e econômico.

Contudo, Bernstein coloca que tanto a formação de uma determinada classe social, como a interiorização do indivíduo na prática do código adotado por esta classe, está diretamente ligada à orientação do sistema familiar, o modo de controle social e o resultado das relações linguísticas. Isso faz com que o código herdado, seja ele, restrito ou elaborado, simbolize a identidade social do indivíduo, além de retratar as características inerentes à forma da classe. ${ }^{20}$

Ademais, quando se analisa o indivíduo competente em informação e no uso de código linguístico, é necessário perceber a importância da individuação do sujeito, da sua representação no meio e das repercussões da informação em contextos éticos e não éticos.

Nessa conjectura, Simondon reconhece que o indivíduo existe enquanto uma apreensão de "uma realidade relativa, uma certa fase do ser que supõe antes dela uma realidade pré-individual". Esta realidade, assinalada em suas proposições, não existe sozinha, mesmo após a individuação, "pois além de a individuação não esgotar de uma só vez os potenciais da realidade pré-individual, aquilo que ela faz aparecer não é somente o indivíduo, mas o acoplamento indivíduo-meio". ${ }^{21}$

O meio e as circunstâncias estão impregnados de informações criadas e emanadas pelos indivíduos, que configuram o social e regressam ao ser singular, influenciando seu comportamento ético na sociedade. Dessa forma, infere-se que a consciência que determinará se uma ação ou uma informação é ética ou não, é a consciência do ser prático-material que recebe, compreende e dissemina o contexto vivenciado para outros dentro da estrutura social. Estabelece-se, então, a lógica do pensamento que se torna a reprodução teórica da dialética originária inerente a cada ser.

Capurro e Hjørland norteiam tais reflexões quando preceituam que informação é "uma categoria antropológica que diz respeito ao fenômeno de mensagens humanas, cujas estruturas verticais e horizontais estão relacionadas ao conceito grego de mensagem (angelia), bem como ao discurso filosófico (logos)".22

Dito isso, com o objetivo de evidenciar vertentes que envolvem competência em informação, ética, códigos e, informação, direciona-se tais perspectivas para identificar, em certa passagem da obra de Marx "o 18 de Brumário de Luís Bonaparte", conjecturas indutoras de tais premissas, sem que o autor faça qualquer menção

\footnotetext{
${ }^{19}$ Elmborg, James. 87, tradução nossa

${ }^{20}$ Bernstein, Basil: Class, codes and control. 106-107

${ }^{21}$ Simondon, Gilbert: A individuação à luz das noções de forma e de informação. 2

${ }^{22}$ Capurro, Rafael; Hjørland, Birger: O conceito de informação. 161
} 
a esses termos. Marx faz ilações sobre indivíduo, luta de classes e partidos políticos, perpassando a situação política da época. $\mathrm{O}$ autor infere percepções sobre a analogia existente entre a vida privada, na qual "se costuma diferenciar entre o que uma pessoa pensa e diz de si mesma e o que ela realmente é e faz" e as lutas históricas, nas quais se identifica que quanto mais os partidos políticos exacerbam fraseologias e ilusões nutridas sobre seu verdadeiro organismo e seus reais interesses, eles terminam por estar em oposição à realidade de suas concepções. ${ }^{23}$

Eagleton faz saber que Marx "estava ciente de que as ideias que realmente prendem homens e mulheres surgem da prática rotineira, não do discurso de filósofos ou de sociedades debatedoras". O autor salienta, ainda, que "quem quiser saber aquilo em que homens e mulheres creem precisa dar uma olhada no que eles fazem, não no que dizem". ${ }^{24}$

Assim, a dialética da ciência moral concernente à política referenda também a economia no sistema capitalista, determinando sua função de

"Proteção do modo de produção e das estruturas de classe em cada tipo de sociedade: cada modo de produção gera determinadas ideias e sentimentos sobre o bem e o mal, que são necessários para manter esse modo de produção. Tudo o que constitua forma de o manter é moralmente bom; tudo o que possa pô-lo em perigo ou contrariá-lo é moralmente mau. Ora, como na sociedade burguesa há luta de classes, há necessariamente uma moralidade de classe - conservadora ou revolucionária. Existe assim um relativismo da moral: a moralidade burguesa é uma coisa e a moralidade proletária é outra, porque para esta é justo tudo aquilo que conduzir à derrota da burguesia e à vitória do proletariado - mesmo que para tanto seja preciso mentir, trair, matar ou roubar, atitudes que a moral burguesa condena". ${ }^{25}$

Percebe-se, nesse entrecho, que, para reconhecer as peculiaridades éticas nas contendas existentes na economia capitalista, onde persistem os papeis de dominador e dominado, explorador e explorado, faz-se necessário conhecer a ideologia político-econômica que norteia a classe hegemônica, para reunir as informações indispensáveis à articulação de estratégias dentro do sistema.

Assim, Marx faz ponderações no sentido que a mesma verdade não serve a dois senhores, quando estes estão em estruturas diferentes.

"No elemento governamental do poder legislativo, a inacessível singularidade empírica do príncipe tomou forma terrena em um certo número de personalidades limitadas, palpáveis, responsáveis; no elemento estamental, a sociedade civil tomou forma celeste em um certo número de homens políticos. Os dois lados perderam sua intangibilidade. O poder soberano perdeu o seu inacessível, exclusivo, Uno empírico; a sociedade civil perdeu seu inacessível, vago, Todo empírico; um a sua rigidez, a outra sua fluidez. No elemento estamental, de um lado, e no elemento governamental do poder legislativo, de outro, que pretendiam juntos mediar sociedade civil e príncipe, a oposição parece, portanto, ter se tornado primeiramente uma oposição belicosa, mas também uma contradição irreconciliável". ${ }^{26}$

\footnotetext{
${ }^{23}$ Marx, Karl: o 18 de Brumário de Luís Bonaparte. 60-61

${ }^{24}$ Eagleton, Terry: Marx estava certo. 49

${ }^{25}$ Amaral, Diogo Freitas do: História das Ideias Políticas. 164

${ }^{26}$ Marx, Karl: Critica da Filosofia do Direito de Hegel. 108
}

\section{Carla Viola:}




\section{Conclusão}

Inicialmente, teceu-se considerações sobre a ética de Aristóteles, por entender que, mesmo de forma secundária, esses pressupostos serviram para a fundamentação da crítica à economia política elaborada por Marx. Percebe-se que o autor considerava que a ética, como qualquer outro componente da superestrutura, estava condicionada pelo modo de produção dominante, defendendo que "não é a consciência que determina a vida, mas a vida que determina a consciência". ${ }^{27}$

Em consonância com tal questão, Eagleton salienta que "Marx acreditava que a ética que governa a sociedade capitalista - a ideia de que só poderei servir a você se isso for lucrativo para mim - era uma forma detestável de vida"28.

Em comunhão com os fundamentos da ciência moral, Marx aduz que a ética se evidenciava de maneira mais óbvia na convivência entre indivíduos a partir da observação de suas atitudes cotidianas e não devido a discursos superficiais e eventuais, da mesma forma que o partido político se concebe ético a partir de sua realidade fática e não em razão de intenções forjadas pelos dominantes.

Nesse sentido, presume-se que Marx tentava demonstrar que faltava, à classe dominada, competência em informação para mais entendimento sobre o código linguístico elaborado e utilizado pela classe dominante, a partir de sua ética de poder e acumulação de capital.

Assim, o estudo da ética, em conexão com as informações que envolvem um Estado precursor das perspectivas econômicas e político-morais almejadas pela sociedade na perspectiva marxiana, representa um desafio para os estudiosos da área. O movimento que se institui sobre a ética em informação deve ser acompanhado pela competência em informação, agregada ao conhecimento mais apurado possível das situações concretas, nas quais se dão as práticas informacionais bem como os limites, potencialidades, agentes e interesses envolvidos.

Nesse contexto, Schneider faz relevantes considerações.

"Também sabemos que o conhecimento é uma produção social, um patrimônio da humanidade - pois para o seu desenvolvimento não foram e são necessários somente os "gênios criadores", mas gerações de multidões anônimas que permitiram e permitem a esses "gênios" trabalhar. Deve, portanto, servir a todos, constituindo-se em instrumento de libertação e melhoria da vida de todos". ${ }^{29}$

A ética, quando referenda a política, se dispõe como normativa para a sociedade e, ao se harmonizar com a economia, representa a fundamentação dos costumes que resultam em ações da classe dominada tentando conciliar seus interesses singulares e particulares com as universalidades das informações emanadas pela classe dominante. É importante notar que a ética pode ser evidenciada pela natureza do ser, pelo exercício do hábito e pelo conhecimento das práticas morais costumeiras.

Tal questão justifica a compreensão de Aristóteles de que "cada indivíduo julga corretamente o que conhece, sendo disso um bom juiz". ${ }^{30} \mathrm{Em}$ harmonia com tal assertiva, conclui-se que Marx inferiu considerações sobre ética, capital e luta de classes buscando a articulação dos saberes individuais com a ciência moral em sentido

\footnotetext{
${ }^{27}$ Marx, Karl: A ideologia Alemã. 94

${ }^{28}$ Eagleton, Terry: Marx estava certo. 95

${ }^{29}$ Schneider, Marco. A Dialética do Gosto. 214-215

${ }^{30}$ Aristóteles: Ética Nicômaco. 48
}

\section{Carla Viola:}


universal. Atenta-se para suas singularidades, nas diversas práticas informacionais que se sobressaem nas luta de classes em cada contexto particular, propiciando a adaptação do objeto, o aproveitamento do uso prático e a eficácia do resultado evidenciado em um sistema capitalista.

\section{Referências}

Amaral, Diogo Freitas do: História das Ideias Políticas. Vol. II, Lisboa: Almedina, 1.ed., 1998.

Aristóteles: Ética a Nicômaco. Série Clássicos, tradução, textos adicionais e notas Edson Bini, São Paulo: Edipro, 2014. Association of College and Research Libraries (CC BY-NC-SA 4.0): Framework for Information Literacy for Higher Education. Filed by the ACRL Board on February 2, 2015. Adopted by the ACRL Board, January 11, 2016.

Bernstein, Basil. Class, codes and control, v.1, Theoretical Studies towards a Sociology of Language, Londres: Routledge, 2003.

Capurro, Rafael; HJORLAND, Birger: O Conceito de Informação. Perspectivas em Ciência da Informação, v. 12, n. 1, p. 148-207, jan./abr. 2007.

Eagleton, Terry: Marx estava certo. Rio de Janeiro: Nova Fronteira, 2012. Disponível em: <http://lelivros.space/book/download-marx-estava-certo-terry-eagleton-em-epub-mobi-e-pdf/>. Acesso em: 20 mar. 2017.

Elmborg, James: Critical Information Literacy: Definitions and Challenges. Association of College \& Research Libraries: Chicago, IL, 2012.

Marcondes, Danilo: Textos básicos de ética: de Platão a Foucault. Rio de Janeiro: Zahar, 2007.

Marx, Karl: A ideologia alemã. São Paulo: Boitempo Editorial, 2007.

: Crítica da Filosofia do Direito de Hegel. São Paulo: Boitempo, 3.ed., 2013.

: Grundrisse. São Paulo: Boitempo, 2011 a.

: O 18 de Brumário de Luís Bonaparte. São Paulo: Boitempo, 2011 b.

Sanchez Vázquez, Adolfo: Ética. Rio de Janeiro, Editora Civilização Brasileira, 2014.

Schneider, Marco: A Dialética do Gosto: Informação, Música e Política. Rio de Janeiro: FAPERJ/Circuito, 2015. Simondon, Gilbert: A individuação à luz das noções de forma e de informação: Introdução. pp. 23-36, 2005.

Wilden, Anthony: Informação, Enciclopédia Einaudi. v. 34, Lisboa: Imprensa Nacional, pp. 11- 77, 2001. 